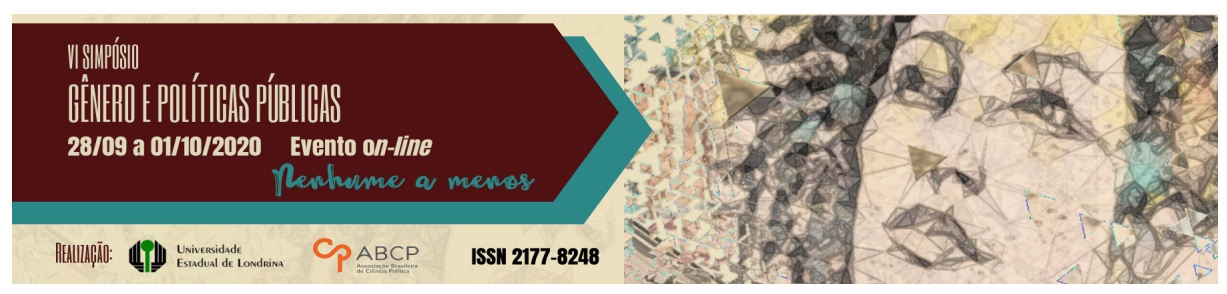

\title{
Discriminação e invisibilidade: análise dos serviços de saúde pública LGBTQI+ em Barra do Garças - MT $^{1}$
}

Morgana Naiara Barbosa Moraes²; Luís Antonio Bitante Fernandes³

\section{Resumo}

Nesta comunicação trazemos um recorte de uma pesquisa intitulada: "Política Nacional de Saúde Integral de Lésbicas, Gays, Bissexuais, Travestis e Transexuais (LGBT) na atenção à saúde em Barra do Garças - MT", realizada desde 2018, tem por objetivo avaliar a integralidade da assistência à saúde de populações LGBT, propiciadas pela rede de saúde pública do município de Barra do Garças. Aqui propomos apresentar análises da presença de discriminação e invisibilidade da população LGBTQI+ nos serviços de saúde pública municipal, correlacionando esses fatores com as consequências diretas na qualidade de vida e promoção de saúde dessa população. Utilizou-se uma abordagem qualitativa e de caráter descritivo, por meio de entrevistas semiestruturadas para a coleta de dados e posteriormente uma análise de conteúdo destas informações. Onde apresenta-se verdadeiramente uma carência no que se trata de uma política pública equitativa de largo alcance na sociedade, a fim de possibilitar a todos o acesso aos seus direitos básicos.

Palavras-chave: população lgbtqi+; política pública de saúde; atenção integral à saúde.

\footnotetext{
1 Artigo escrito em meio a pandemia de COVID-19, causada pelo coronavírus da síndrome respiratória aguda grave 2 (SARS-CoV-2). Mais que um problema sanitário, a Pandemia levou parte da população privilegida ao isolamento social; outra parte da sociedade, aquels que sempre foram invibilizads ficou fadada ao total esquecimento.

2 Graduada em Biomedicina pela Universidade Federal de Mato Grosso/CUA; Mestranda pelo Programa de Pós-graduação em Sociologia - PPGS/ICHS/UFMT Cuiabá. E-mail: naiiaramoraes@outlook.com

3 Doutor em Sociologia, professor do ICHS/CUA/UFMT e do Programa de Pósgraduação em Sociologia - PPGS/ICHS/UFMT - Cuiabá. E-mail: bitante67@hotmail.com
}

GT 06 - Gênero, cuidado e políticas de saúde 


\title{
Discrimination and invisibility: analysis of LGBTQI+ public health services in Barra do Garças - MT
}

\begin{abstract}
In this communication we bring a cutout from a research entitled: "National Integral Health Policy for Lesbians, Gays, Bisexuals, Transvestites and Transsexuals (LGBT) in health care in Barra do Garças - MT", carried out since 2018, aims to evaluate the integrality of health care for LGBT populations, provided by the public health network of the municipality of Barra do Garças. Here we propose to present analyses of the presence of discrimination and invisibility of the LGBTQI+ population in municipal public health services, correlating these factors with the direct consequences on the quality of life and health promotion of this population. A qualitative and descriptive approach was used, by means of semi-structured interviews for data collection and subsequently an analysis of the content of this information. Where there is a real lack in what concerns an equitable public policy of wide scope in society, in order to enable everyone to have access to their basic rights.
\end{abstract}

Keywords: lgbtqi+ population; public health policy; integral health care.

\section{Introdução}

A população de Lésbicas, Gays, Bissexuais, Travestis/Transgêneros, Queer, Intersexuais e demais definições (LGBTQI+), se apresenta como movimento social bem antes de adotar tal nomenclatura tão inclusiva. Passando por diversos marcos históricos que levaram ao conhecimento conquistados atualmente, todo processo evolutivo do movimento foi definido por uma busca incessante de igualdade e respeito. Um âmbito sempre presente nesse processo é a esfera da saúde, dada como um direito assegurado e acessível, ressaltado pela criação de um sistema de atendimento público. E por mais retrocessão que isto possa parecer, vários níveis de opressão acabam por ser constantemente retratados nesse cenário. O abismo entre teoria e prática se torna gradativamente mais gritante e suas consequências, notórias.

Diante disso, a proposta do trabalho pauta-se na apresentação 
dos resultados de pesquisa desenvolvida acerca da saúde pública LGBTQI+, na cidade de Barra do Garças - MT. O objetivo da pesquisa fundamentou-se em analisar a presença de discriminação e invisibilidade à população LGBTQI+ nos serviços de saúde pública municipal, correlacionando esses possíveis fatores com as consequências diretas na qualidade de vida e promoção de saúde dessa população.

Para seguirmos a análise acerca da saúde pública para população LGBTQI+, partiremos do conhecimento sobre a existência de programas específicos para esse público, como o programa Brasil Sem Homofobia (BSH), vigente desde 2004, e a Política Nacional de Saúde Integral de Lésbicas, Gays, Bissexuais, Travestis e Transexuais (PNSILGBT), vigente desde 2011. Medidas essas com intuito de destacar não só as urgências dessa população em termos de enfermidades físicas, mas também propõe um olhar mais aguçado no sentido de todo contexto que a cerca.

\section{Conceitos introdutórios a temática}

Avançando sobre o tema, a Organização Mundial da Saúde (OMS) (2016) atribui esta definição quanto à sexualidade:

é um aspecto central do ser humano ao longo da vida que engloba sexo, identidades e papéis de gênero, orientação, erotismo, prazer, intimidade e reprodução. A sexualidade é influenciada por interseção biológica, psicológica, social, econômica, política, cultural, jurídica, fatores históricos, religiosos e espirituais (WHO, 2016).

Contrastando com o que já se conhecia sobre sexualidade, dois termos surgem para salientar com mais afinco as diferenças presentes nesse contexto: sexo - considerado como dado biológico - e gênero. Assim a definição de sexo proveria de uma conotação anatômica, enquanto gênero se definiria com base em características socioculturais. 
Estudos na área de gênero, mais recentes, apontam para a necessidade de se olhar para o gênero em uma abordagem que transborda essa dicotomia em um processo de desconstrução da categoria (MENEZES et al, 2010; SCOTT, 2002; BUTLER, 2011).

Após a elucidação do contexto histórico relevante ao tema, é dado enfoque para outro tópico de suma importância: direitos básicos da população LGBTQI+, com ênfase na esfera da saúde.

Legalmente, a Constituição garante no Art. 196, “a saúde é direito de todos e dever do Estado, garantido mediante políticas sociais e econômicas que visem à redução do risco de doença e de outros agravos e ao acesso universal e igualitário às ações e serviços para sua promoção, proteção e recuperação". Na ideia de regularizar o capítulo constitucional da saúde, foram promulgadas as Leis 8.080/90 e 8.142/90, que asseguram o conceito ampliado de saúde e resignam princípios, com destaque para o do Cap. II, Art. $7^{\circ}$, alínea IV, quanto à "igualdade da assistência à saúde, sem preconceitos ou privilégios de qualquer espécie". Entendido assim que toda e qualquer pessoa tem o direito ao recebimento do mais alto nível de saúde física e mental, sem sofrer qualquer tipo de discriminação ou atitude baseada em sua orientação sexual ou identidade de gênero que resulte na privação desse direito. A saúde sexual e reprodutiva é um aspecto fundamental desse direito (BRASIL, 1988; PRINCIPLES, 2007).

Consoante a OMS, entende-se por saúde sexual muito além da mera inexistência de enfermidades. $O$ conceito se forma a partir de um estado físico, uma harmonização entre fatores como bem-estar emocional, mental e social em relação à sexualidade. Assim, a torna fator determinante para categorizar um indivíduo devidamente pleno e saudável, onde se compreende uma necessária efetivação livre de toda e qualquer manifestação de violência, discriminação e opressão desses direitos sexuais que competem a todos os seres humanos, independente do contexto; assegurando a todos uma saúde protegida, respeitosa e segura. O reconhecimento de tais práticas objetiva essas medidas 
governamentais a não só reconhecerem, mas também se empenharem ao máximo em transpor todos esses obstáculos para o gozo pleno da saúde dessas pessoas (WHO, 2006, 28-31; FERRAZ; KRAICZYK, 2017).

\section{Saúde pública LGBTQI+ em Barra do Garças - MT}

O munícipio possui uma população de 60.661 habitantes, onde encontra-se um polo universitário, abrangente em diversidade sexual e de gênero. Além do que, cabe considerar o município como parte integrante de um estado que somente em 2017 trouxe iniciativas LGBTQI+ (IBGE, 2018; ARAGUSUKU; LOPES, 2018).

Primeiramente, traçou-se um perfil sociocultural das duas populações entrevistadas, um total de 13 participantes. Alguns entrevistados não foram incluídos por não terem sido coletados dados suficientes para delinear o perfil dos mesmos. Ao que consta sobre a população de profissionais de saúde, a amostra foi constituída por 7 profissionais de saúde sendo 3 enfermeiras-chefe, 1 enfermeira e 3 agentes de saúde. Notou-se que os profissionais de saúde têm idade predominantemente na faixa etária entre 35 e 45 anos, com uma predominância do gênero feminino. Vale ressaltar também que em sua maioria, possuem experiência na área e um abrangente tempo de atuação nos cargos que executam (entre 2 e 8 anos).

Ao seguirmos para a população de usuários LGBTQI+, a amostra foi constituída no intuito de contemplar o máximo possível da diversidade contida nesta sigla. Então foi obtido a participação de 2 homoafetivos (gays), 1 homoafetiva (lésbica), 1 pansexual e 2 homens transgêneros. Pôde-se observar variações em praticamente todas as variáveis socioeconômicas deste grupo. Enfatizou-se não só uma diversidade em questão de sexualidade e gênero, mas também em áreas da graduação e âmbito religioso. Todas as características individuais de cada entrevistado corroboram com as diferentes visões demonstradas 
sobre o tema da pesquisa.

Prosseguindo para o aprofundamento do conteúdo das entrevistas, partimos para o primeiro bloco temático, onde propôs-se realizar um questionamento a respeito do conhecimento dos profissionais de saúde sobre a atuação do governo municipal para implementação, implantação e avaliação da política pública beneficiando a população LGBTQI+. Desta forma, os dados mostram que há uma total falta de conhecimento relevante a pergunta: "Não existe politica, né? Eu nunca participei de nada, não sei como está essa questão." (Ent. 1), "Até onde eu sei, não está havendo nenhum tipo de discussão sobre esse tema. Pode ter acontecido no que diz respeito aos órgãos municipal ou estadual, mas não fiquei sabendo." (Ent. 2).

Ao abordarmos sobre capacitação, apenas uma entrevistada realizou um tipo de capacitação. Foi relatado que costumeiramente não há disseminação de informações sobre capacitações seja online ou presencial e, diretamente, essa ausência de capacitação tem efeitos atrelados ao despreparo para com o público. Assim como podemos ver exemplos nessa fala: "Aqui a gente, é igual eu te falei, os treinamentos dificilmente acontecem... Nunca me informaram, eu não sei." (Ent. 4).

Quando indagado quanto aos obstáculos internos e externos sentidos pelos profissionais no momento de desempenhar essas políticas para a população LGBTQI+, recorrentemente atribuiu-se a uma invisibilidade muito constante à noção de políticas específicas para o público LGBTQI+, além da falta maior de espaço físico adequado, de recursos humanos, de planejamento. Contudo, de maneira contraditória, ao ser discutida a qualidade dos serviços ofertados por suas unidades, os profissionais se mostram orgulhosos e crédulos que efetuam suas atribuições de maneira conveniente. De maneira mais marcante para este bloco temático, temos a fala da entrevistada 1:

- "A dificuldade é porque não existe uma política que venha lá de cima, né? Do governo. Nós não criamos políticas dentro da unidade, programas 
existem e a gente executa. São várias esferas, a gente fica na parte de execução, mas ainda não existem políticas para a inserção de pessoas dessa categoria [...]." (Ent. 1)

Seguindo pela perspectiva dos usuários, eles caracterizaram diferentes entraves em relação ao seu acesso a saúde pública. Por exemplo, a credulidade no despreparo desde a formação acadêmica desses profissionais, a invisibilidade acarretada pela heteronormatividade, o não uso do nome social em algumas Unidades Básicas de Saúde, entre outras. Situações como essas ferem gravemente direitos básicos que podem ser encontrados na Carta dos Direitos dos Usuários da Saúde, onde é assegurado para seus usuários um atendimento livre de qualquer restrição ou negação em razão de sua identidade de gênero.

Pautando sobre a informação e divulgação de ações da Política Nacional de Saúde Integral de Lésbicas, Gays, Bissexuais, Travestis e Transexuais por meio da Secretaria Municipal de Saúde, apenas a entrevistada 2 afirmou receber divulgação por meio de cartazes, folders, e até por áudio visual. Construindo um discurso incoerente em seguida, ao alegar que não há ações voltadas diretamente para população LGBTQI+ em sua unidade. Alegação essa compartilhada pelos demais profissionais de saúde entrevistados. Conjuntamente neste bloco temático, a classe de profissionais foi questionada acerca de sua consciência referente a colocações sobre a PNSILGBT no Conselho de Saúde e Conferência de Saúde, os mesmos mencionaram que não ocorreu nenhuma discussão sobre o tema nestes eventos.

Deslocando nosso olhar para questões reservadas aos usuários LGBTQI+, abordamos sobre a presença do preconceito na esfera da saúde e suas expressões. É possível destacar diferentes relatos provenientes dos participantes, onde citaram o ato de fazer "piadinhas", a invisibilidade sofrida pelas diversas sexualidades, o nível de profissionalismo que varia conforme o local onde o serviço é prestado, a falta de compreensão e empatia por parte de alguns funcionários, e de 
modo geral, a obstaculização da doação de sangue para a população LGBTQI+.

No momento em que se perguntou o posicionamento deles ao que se diz dessa obstaculização em doar sangue, todos os entrevistados exprimem um sentimento claro de inferiorização e a colocam como uma maneira de condicionar a população LGBTQI+ a um status de promiscuidade, constantemente ligada as infecções sexualmente transmissíveis (IST's). Esses sentimentos podem ser observados ao longo da fala do entrevistado 9:

- “É algo que está muito ligado a essas coisas, como se fosse o lixo da humanidade. Então foi feita uma propaganda em prol disso. $\mathrm{O}$ fato de você dizer que você é uma mulher que quer passar o resto da sua vida com uma mulher, parece que torna esse afeto a coisa mais monstruosa do mundo, por conta de que foi construído assim. [...]" (Ent. 9)

Adentrando na temática "conservadorismo presente na saúde", foi perguntado aos usuários se eles o consideram um fator para o agravamento do estado de saúde da pessoa LGBTQI+. Todos os entrevistados acreditam que toda e qualquer forma de discriminação interfere fundamentalmente no processo saúde-doença da pessoa LGBTQI+, estabelecendo que cogitem como fator determinante para o conceito de agravamento de saúde. Podendo-se estipular o quão atingido é a subjetividade do indivíduo mediante a uma interferência deletéria em sua saúde, já estando prejudicada por alguma enfermidade ou não.

\section{Considerações finais}

O distanciamento entre as práticas estabelecidas com o que é cumprido no cotidiano torna o cenário assombroso. A continuada contradição demonstrada pelos profissionais de saúde releva um dos maiores obstáculos para a efetuação plena de seus serviços: a hipocrisia 
social. O fato de não saberem o que lhes compete, instantaneamente compromete seu desempenho, mas também se demonstra a falta de interesse em aprimorar os serviços, buscar meios de estender esse bom atendimento. Reduz-se as chances de uma boa atuação quando o funcionário nem ao menos sabe o que lhe é atribuído, cedendo ainda mais espaço para o desinteresse governamental frequentemente presente na sociedade.

A permanência da desinformação nesta esfera revela não só a intenção das autoridades na manutenção dessa situação, mas também expõe o descaso predominante em vários níveis. Partindo da subordinação imposta pela hierarquia desses setores, nota-se dois comportamentos principais entre os profissionais de saúde: a insatisfação com o modo que é conduzida esta esfera e a alienação dos mesmos combinada com a falta de interesse sobre o tema.

Tendo como norteador a Política Nacional de Saúde Integral de Lésbicas, Gays, Bissexuais, Travestis e Transexuais, válida desde 2011, o estudo demonstra que ainda no período atual, vários direitos desta população são violados. Os resultados dão voz às pessoas LGBTQI+ que relataram como em inúmeras vezes se sentiram subjugadas, desrespeitadas e invisibilizadas; permitindo a ilustração da realidade destas pessoas que procuram esses atendimentos e como a realização desses processos afeta esse público. Consequências que interferem tanto na qualidade de vida desses indivíduos, quanto podem servir como agravante do estado de saúde, havendo um processo de adoecimento ou a ausência dele.

Sugerindo então como estratégias na tentativa de diminuir as discrepâncias apresentadas na área, a promoção mais assídua de capacitações para seus profissionais, por meio presencial, semipresencial e online, reforçando os meios já existentes de se capacitar. Além de instaurar uma divulgação efetiva sobre os direitos dessa população na saúde, informando através de cartazes e folders a política pública LGBT. Propõe-se as autoridades municipais um empenho maior 
para a construção de uma unidade referencial em tratamento para travestis e transgêneros, tendo como justificativa o fato de que o Processo Transexualizador do SUS não conta com um estabelecimento de saúde habilitado para atendimento especializado no estado de Mato Grosso.

Por fim, concluímos segundo a realização da pesquisa, uma existência de falhas na garantia e incentivo dos direitos relacionados à saúde da população LGBTQI+. Demonstra-se a urgência em mudanças nos aspectos de conduta, conhecimento e aprimoramento no que se refere às práticas definidas pela política nacional de saúde LGBT. A fim de fato que uma equidade possa alcançar verdadeiramente essa população, e assim, não mais tenham que travar lutas para conquistar aquilo que lhes é de direito.

\section{Referências}

ARAGUSUKU, Henrique Araújo; LOPES, Moisés Alessandro de Souza. Políticas públicas e cidadania LGBT em Mato Grosso: Uma década de avanços e retrocessos (2007-2017). Sexualid, Salud y Sociedad, Rio de Janeiro, v. 29, p. 147-171, 2018.

BRASIL, Senado Federal. Constituição da república federativa do Brasil. Brasília, 1988.

BUTLER, Judith. Gender trouble: Feminism and the subversion of identity. Routledge. Routledge, 2011.

FERRAZ, Dulce; KRAICZYK, Juny. Gênero e Políticas Públicas de Saúde- construindo respostas para o enfrentamento das desigualdades no âmbito do SUS. Revista de Psicologia da UNESP, v. 9, n. 1, p. 70-82, 2017.

IBGE - Instituto Brasileiro de Geografia e Estatística. População Estimada. Disponível em: https://www.ibge.gov.br/cidades-eestados/mt/barra-do-garcas.html.

MENEZES, Aline Beckmann; BRITO, Regina Célia Souza; HENRIQUES, Alda Loureiro. Relação entre gênero e orientação sexual a partir da 
perspectiva evolucionista. Psicologia: Teoria e Pesquisa, v. 26, n. 2, p. 245-252, 2010.

PRINCIPLES, Yogyakarta. The Yogyakarta Principles. Principles on the Application of International Human Rights Law in Relation to Sexual Orientation and Gender Identity. Adopted by the Intcrmuiona, p. 6-9, 2007.

SCOTT, Joan. A cidadã paradoxal: as feministas francesas e os direitos do homem. Editora Mulheres, 2002.

WORLD HEALTH ORGANIZATION, et al. Defining sexual health: report of a technical consultation on sexual health: 28-31 January 2002, Geneva. World Health Organization, 2006.

WORLD HEALTH ORGANIZATION, et al. FAQ on Health and Sexual Diversity - An Introduction to Key Concepts. World Health Organization. Geneva, 2016. 